www.jmscr.igmpublication.org

Impact Factor (SJIF): 6.379

Index Copernicus Value: 71.58

ISSN (e)-2347-176x ISSN (p) 2455-0450

crossref DOI:_https://dx.doi.org/10.18535/jmscr/v6i2.23

Journal Of Medical Science And Clinical Research

IGM Publication

An Official Publication of IGM Publication

\title{
Safety and Efficacy Profile of Oral Tranexamic Acid v/s Tranexamic Acid Soaks v/s Tranexamic Acid Cream in Treatment of Melasma - A Hospital Based Prospective Randomised Controlled Comparative Study
}

\author{
Authors
}

Shraddha J. Patil ${ }^{1}$, Varsha Jamale ${ }^{2}$, Mohan Kale ${ }^{3}$, Balkrishna Nikam ${ }^{4}$, Asma Hussain ${ }^{5}$, Natasha Vijayendran ${ }^{6}$

${ }^{1,6}$ Junior Resident (Dermatology), Krishna Institute of Medical Sciences, Karad, Maharashtra

${ }^{2}$ Associate Professor (Dermatology), Krishna Institute of Medical Sciences, Karad, Maharashtra

${ }^{3}$ Professor and Head of the Dept (Dermatology), Krishna Institute of Medical Sciences, Karad, Maharashtra

${ }^{4,5}$ Assistant Professor (Dermatology), Krishna Institute of Medical Sciences, Karad, Maharashtra

Corresponding Author

Shraddha J. Patil

Department of Dermatology, Krishna Institute of Medical Sciences, Karad, Maharashtra, India-415110

Email: shraddhapatil.sjp@gmail.com, Phone No- 8412914684

\begin{abstract}
Background: Melasma is an acquired hypermelanosis; treatment of which is challenging. Tranexamic acid is new modality for melasma. This is the first clinical study comparing single drug tranexamic acid in three different forms i.e. oral, soaks and cream in treatment of melasma.

Aim: The present study was conducted to evaluate the safety and efficacy profile of oral tranexamic acid $v / s$ tranexamic acid soaks $v / s$ tranexamic acid cream in the treatment of melasma.

Materials And Methods: 90 patients of melasma were enrolled in the study. They were divided into three groups. 30 patients were treated with oral tranexamic acid (250 mg twice daily), 30 with tranexanic acid solution (5ml) soaks and 30 with tranexamic acid cream twice daily. Efficacy parameters used were Melasma Area Severity Index (MASI), Physician Global Assessment (PGA) and Visual Analogue Scale (VAS). Efficacy was evaluated fortnightly for a period of twelve weeks.

Results: At the end of the study there was $95.8 \%, 47.6 \%$ and $19.6 \%$ reduction in MASI score in the oral, compresses and cream groups respectively. The response to oral tranexamic acid was more efficacious compared to tranexamic acid soaks which showed fairer results and then tranexamic acid cream. The difference was statistically significant ( $p<0.05)$. The side effects were minimal and did not necessitate withdrawal of treatment.

Conclusion: Oral tranexamic acid, tranexamic acid soaks and tranexamic acid cream are efficacious in the treatment of melasma. However, oral tranexamic acid is more efficacious followed by soaks and then the cream which is least effective.

Keyword: Melasma, Tranexamic acid.
\end{abstract}

\section{Introduction}

Facial hyper pigmentation is usually a reflection of an increased amount of melanin either within the epidermis, the dermis, or both (mixed pattern). These disorders usually occur due to an increased amount of melanin production and occasionally 
from an increase in the density of active melanocytes. ${ }^{1}$

Melasma is acquired pigmentary disorder characterized by more or less symmetrical distributed, medium-to dark-brown macules with well defined geographic borders, affecting mainly sun exposed areas particularly forehead, cheeks, nose, upper lip and chin. It affects individuals of all races and genders and predominately affects women (Fitzpatric skin type IV-VI). Although melasma is associated with multiple etiological factors (pregnancy, genetic, racial, and endocrine), one of the primary causes appears to be exposure to sunlight. Three patterns of melasma are recognized clinically: (1) centrofacial pattern, (2) malar pattern, and (3) mandibular pattern. Four types of melasma are described on the basis of Wood's lamp examination: (1) an epidermal type, (2) a dermal type, (3) a mixed type, and (4) an indeterminate type.

Different treatment modalities such as chemical peels, dermabrasion, laser therapies and topical depigmenting agents such as hydroquinone have studied and used with limited results and frequent recurrence and treatment complications.

Trans-4-aminomethyl cyclohexanecarboxylic acid (TXA), a synthetic derivative of the amino acid lysine which has an antifibrinolytic effect through the reversible blockade of lysine-binding sites on plasminogen molecules. ${ }^{2}$ The intracellular release of arachidonic acid (AA), a precursor of prostanoid, and the level of alpha-melanocytestimulating hormone increase as the result of plasmin activity. These two substances can activate melanin synthesis. Therefore, the antiplasmin activity of TXA is thought as the main mechanism of hypopigmentory effect of this agent. $^{3,4,5}$ Tranexamic acid orally and in topical form is widely used in treatment of melasma. Tranexamic acid solution compresses have shown good results in reducing redness in rosacea but have not been studied in the literature for melasma. So we took the opportunity to study the efficacy of oral tranexamic acid and compare it with topical modalities of the same.
Application of this study for betterment of patient care is of great significance as the treatment guidelines and various other parameters like safety and improvement of quality of life have been studied here.

\section{Materials and Methods}

Current study is hospital based prospective, randomised controlled, comparative trial conducted in department of Dermatology OPD. A total of 90 patients were enrolled in the study after fulfilling the inclusion and exclusion criteria. Inclusion criteria specified acquired hyper pigmentation on the face located symmetrically. The exclusion criteria ruled out women with a pregnancy or a breastfeeding period, a history of thrombosis, a tendency of blood coagulation ruled out by laboratory tests, unrealistic expectation for the treatment, use of other treatment modalities for melasma, and those not willing for regular follow up due to various reasons.

The patients were divided into three groups. 30 of them received oral tranexamic acid (group O), 30 received tranexamic acid solution compresses (group S) and the other 30 received topical tranexamic acid (group T) for 12 weeks duration. Laboratory investigations like coagulation tests, platelet count, renal function test, serum glutamic oxaloacetic transaminases (SGOT), serum glutamic pyruvate transaminases (SGPT) were performed on all participants and assessments of safety were performed at each follow-up visit. Urinary pregnancy test was performed in all female patients. The response was evaluated fortnightly using clinical photographs and efficacy variables like Melasma Area Severity Index (MASI), Physician Global Assessment (PGA) and Visual Analogue Scale (VAS).

This study was conducted with the prior approval of the Research Ethics Committee.

A student's t-test and ANNOVA test was used to evaluate the changes before and after treatments. Statistical significance was defined as $\mathrm{P}$ value < 0.05 . 


\section{Results}

Female in group $\mathrm{O}$, group $\mathrm{S}$ and group $\mathrm{T}$ were $80 \%, 73.3 \%, 80 \%$ respectively. Males in group O, group S and group T were 20\%, 26.7\%, 20\% respectively. This difference was statistically not significant $(\mathrm{p}>0.05)$.

Mean age was high in group $\mathrm{T}$ (36.73 years) compared to group S (34.57 years) and group O (33.27years), but this difference was statistically not significant $(p>0.05)$. So age of the patients in three groups is comparable. Thus demographic data of all the three groups was comparable at baseline.

Baseline MASI, PGA and VAS were comparable between all three groups

After 15 days, in group $\mathrm{O}$ mean MASI score was significantly reduced to 10.86 , that is $16.1 \%$ reduction from baseline while in group $S$ it reduced to 13.26 , that is $6.5 \%$ reduction and in group $\mathrm{T} 11.51$, that is $2.9 \%$ reduction. Statistically this was not significant. In group O mean PGA also reduced significantly to to $4.07(18.1 \%$ improvement) and mean VAS was reduced to 84.5 that is $15.5 \%$ reduction from baseline VAS. While in group $\mathrm{S}$ mean PGA also reduced significantly to 5.07 (2.5\% improvement) and mean VAS was reduced to 90.7 that is $9.3 \%$ reduction from baseline. In group $\mathrm{T}$ Mean PGA also reduced significantly to $5.53(0.7 \%$ improvement $)$ and mean VAS was reduced to 100 that is $0 \%$ reduction from baseline VAS. Group $\mathrm{O}$ showed better improvement in reducing the MASI as compared group $\mathrm{S}$ and group $\mathrm{T}$. However, there was no statistically difference between the three groups.

After 30 days, in group $\mathrm{O}$ mean MASI score was significantly reduced to 8.25 , that is $36.2 \%$ reduction from baseline while in group $S$ it reduced to 11.97 , that is $15.6 \%$ and in group $\mathrm{T}$ it reduced to 11.05 , that is $6.7 \%$ reduction. In group $\mathrm{O}$ mean PGA also reduced significantly to $3.1(37.6 \%$ improvement) and mean VAS was reduced to 67.0 that is $33 \%$ reduction from baseline VAS. In group S Mean PGA also reduced significantly to 4.17 (19.8\% improvement) and mean VAS was reduced to 81.3 that is $18.7 \%$ reduction from baseline VAS. In group T Mean PGA also reduced significantly to $5.0(10.2 \%$ improvement) and mean VAS was reduced to 88.7 that is $11.3 \%$ reduction from baseline VAS. Group O showed better improvement in reducing MASI, PGA \& VAS score compared to group $\mathrm{S}$ and $\mathrm{T}$. However, there was statistical significant difference between three groups.

After 45 days, group $\mathrm{O}$ mean MASI score was significantly reduced to 5.95 , that is $53.9 \%$ reduction from baseline while in group $\mathrm{S}$ it reduced to 10.52 , that is $25.9 \%$ and in group $\mathrm{T}$ it was 10.57 , that is $10.8 \%$ reduction. Group $\mathrm{O}$ showed better improvement in reducing the MASI, PGA \& VAS as compared to group S and group T. However, there was statistically significant difference between the three groups.

After 60 days, group $\mathrm{O}$ mean MASI score was significantly reduced to 3.51 , that is $72.8 \%$ reduction from baseline while in group $\mathrm{S}$ it reduced to 8.91 , that is $37.2 \%$ and in group $\mathrm{T}$ it reduced to 10.08 , that is $14.9 \%$ reduction. Group $\mathrm{O}$ showed better improvement in reducing the MASI as compared to group $\mathrm{S}$ and group $\mathrm{T}$. However, there was statistically significant difference between the three groups. In study group O mean VAS was reduced to 26.5 that is $73.5 \%$ reduction from baseline VAS and mean PGA also reduced significantly to $1.2(75.8 \%$ improvement) while in group $\mathrm{S}$ mean PGA reduced to 3.13 (39.8\% improvement) and mean VAS was reduced to 62.7 that is $37.3 \%$ reduction from baseline VAS and in group T mean PGA reduced to 4.2 (24.6\% improvement) and mean VAS was reduced to 78.0 that is $22 \%$ reduction from baseline VAS. Group $\mathrm{O}$ showed better improvement in reducing the PGA \& VAS as compared to group $\mathrm{S}$ and group $\mathrm{T}$. There was statistically significant difference between the three groups.

At the end of the study (90 days), in study group mean MASI score was further reduced to 0.54 , that is $95.8 \%$ reduction from baseline, while in group $\mathrm{S}$ it reduced to 7.43 , that is $47.6 \%$ reduction 


\section{JMSCR Vol||06||Issue||02||Page 151-162||February}

and in group $\mathrm{T}$ it reduced to 9.53 , that is $19.6 \%$ reduction. Group $\mathrm{O}$ showed better improvement in reducing the MASI as compared to group $\mathrm{S}$ and group T. However, there was statistically significant difference between the three groups. At the end of the study (90 days), in study group mean VAS was reduced to 4.17 that is $95.83 \%$ reduction from baseline VAS and mean PGA also reduced significantly to $0.23 \quad(95.4 \%$ improvement) while in group $S$ mean PGA reduced to 2.53 (51.3\% improvement) and mean VAS was reduced to 51.8 that is $48.2 \%$ reduction from baseline VAS and in Group T mean PGA reduced to 3.9 (29.9\% improvement) and mean
VAS was reduced to 73.7 that is $26.3 \%$ reduction from baseline VAS. Group $\mathrm{O}$ showed better improvement in reducing the PGA \& VAS as compared to group $\mathrm{S}$ and group $\mathrm{T}$. There was statistically significant difference between the three groups.

Group $\mathrm{O}$, group $\mathrm{S}$ and group $\mathrm{T}$ are efficacious in reducing MASI, PGA \& VAS score in melasma. However, group $\mathrm{O}$ was much more statistically significant followed by group $\mathrm{S}$ and then group $\mathrm{T}$. Side effects seen in group $\mathrm{O}$ were headache which was seen in $6.7 \%$ patients, followed by nausea which was seen in $6.6 \%$ patients. Group $S$ and group T showed no side effects.[Table \& Figure1]

Table 1: Result summary

\begin{tabular}{|l|c|c|c|}
\hline $\begin{array}{l}\text { Parameters } \\
\text { (\% reduction) }\end{array}$ & Group O & Group S & Group T \\
\hline Mean MASI & $95.8 \%$ & $47.6 \%$ & $19.6 \%$ \\
\hline Mean PGA & $95.4 \%$ & $51.3 \%$ & $29.9 \%$ \\
\hline Mean VAS & $95.83 \%$ & $48.2 \%$ & $26.3 \%$ \\
\hline Side effects seen & $13.3 \%$ & Nil & Nil \\
\hline
\end{tabular}

Figure 1: MASI at various time intervals in group $\mathrm{O}$, group $\mathrm{S}$ and group $\mathrm{T}$

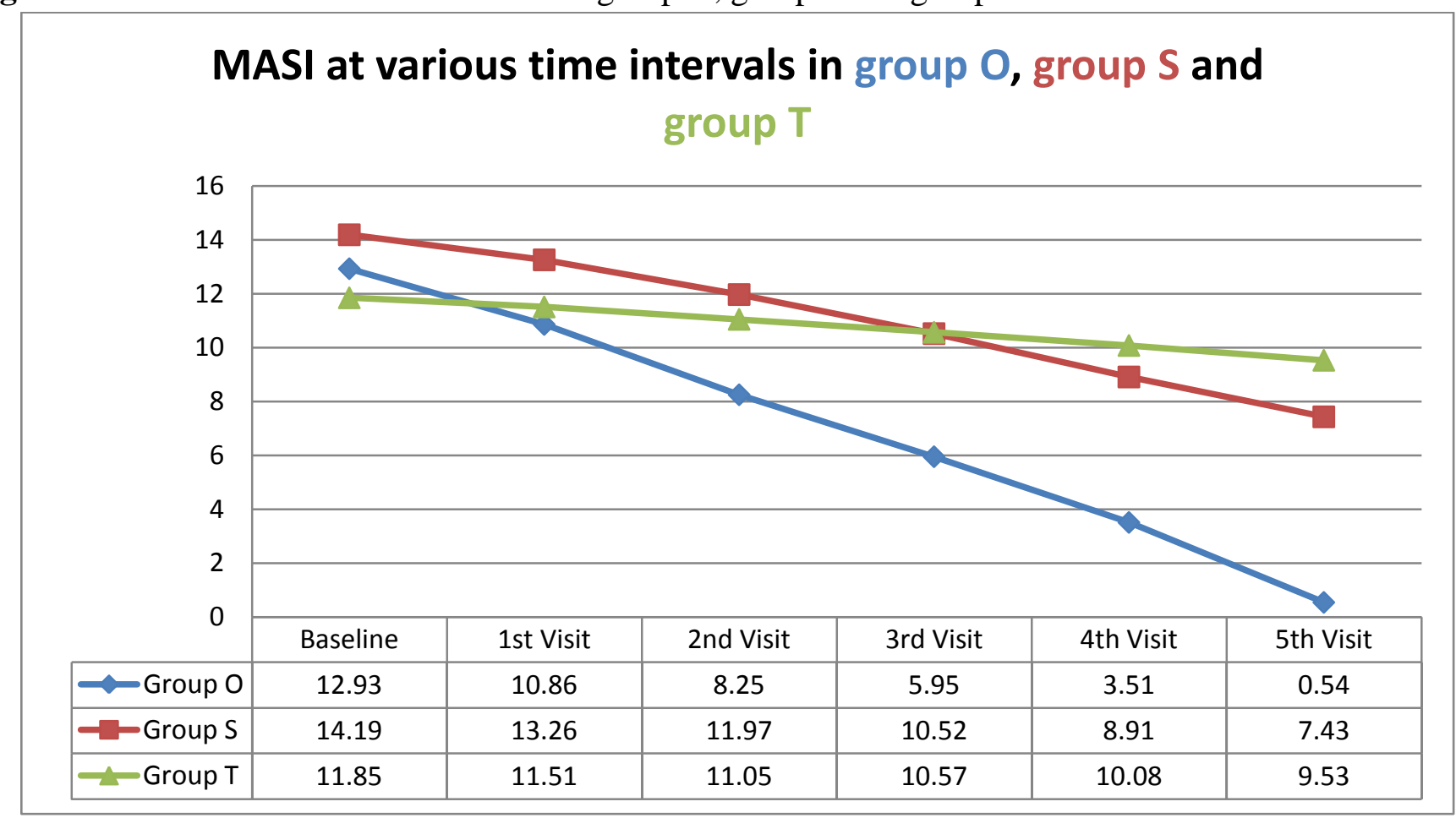

\begin{tabular}{|l|c|c|c|c|}
\hline Comparison & Mean Difference & q value & P value & Inference \\
\hline Group 0 v/s Group S & -6.890 & 8.643 & $<0.001$ & Significant \\
\hline Group 0 v/s Group T & -8.990 & 11.278 & $<0.001$ & Significant \\
\hline Group S v/s Group T & -2.100 & 2.634 & $>0.05$ & Not significant \\
\hline
\end{tabular}




\begin{tabular}{|l|l|}
\hline JMSCR Vol ||06||Issue ||02||Page 151-162||February & 2018 \\
\hline
\end{tabular}

Figure 2 and 3: Photographs of patients treated with Oral Tranexamic acid
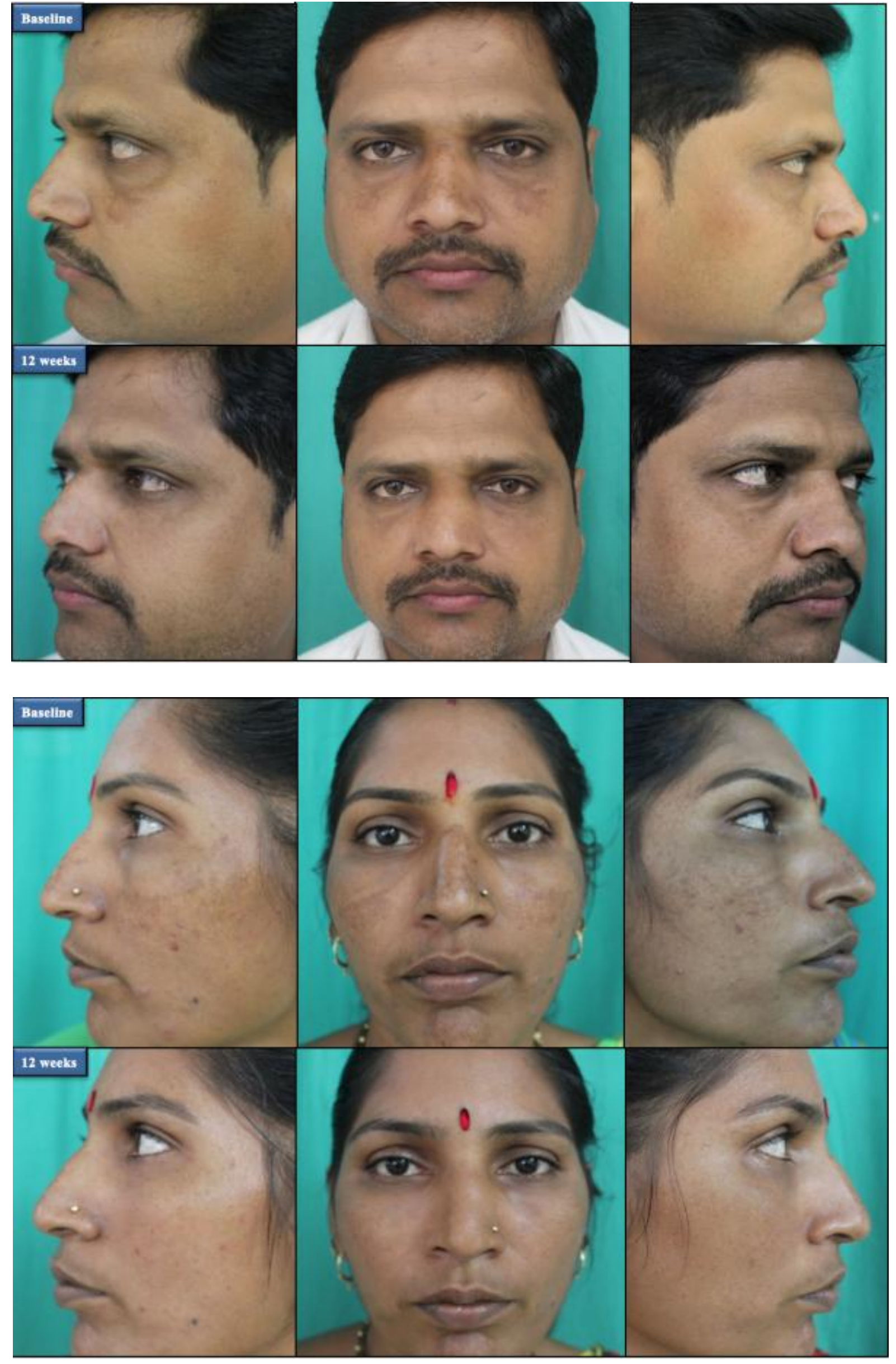


\section{JMSCR Vol||06||Issue||02||Page 151-162||February}

Figure 4 and 5: Photographs of patients treated with Tranexamic acid Soaks
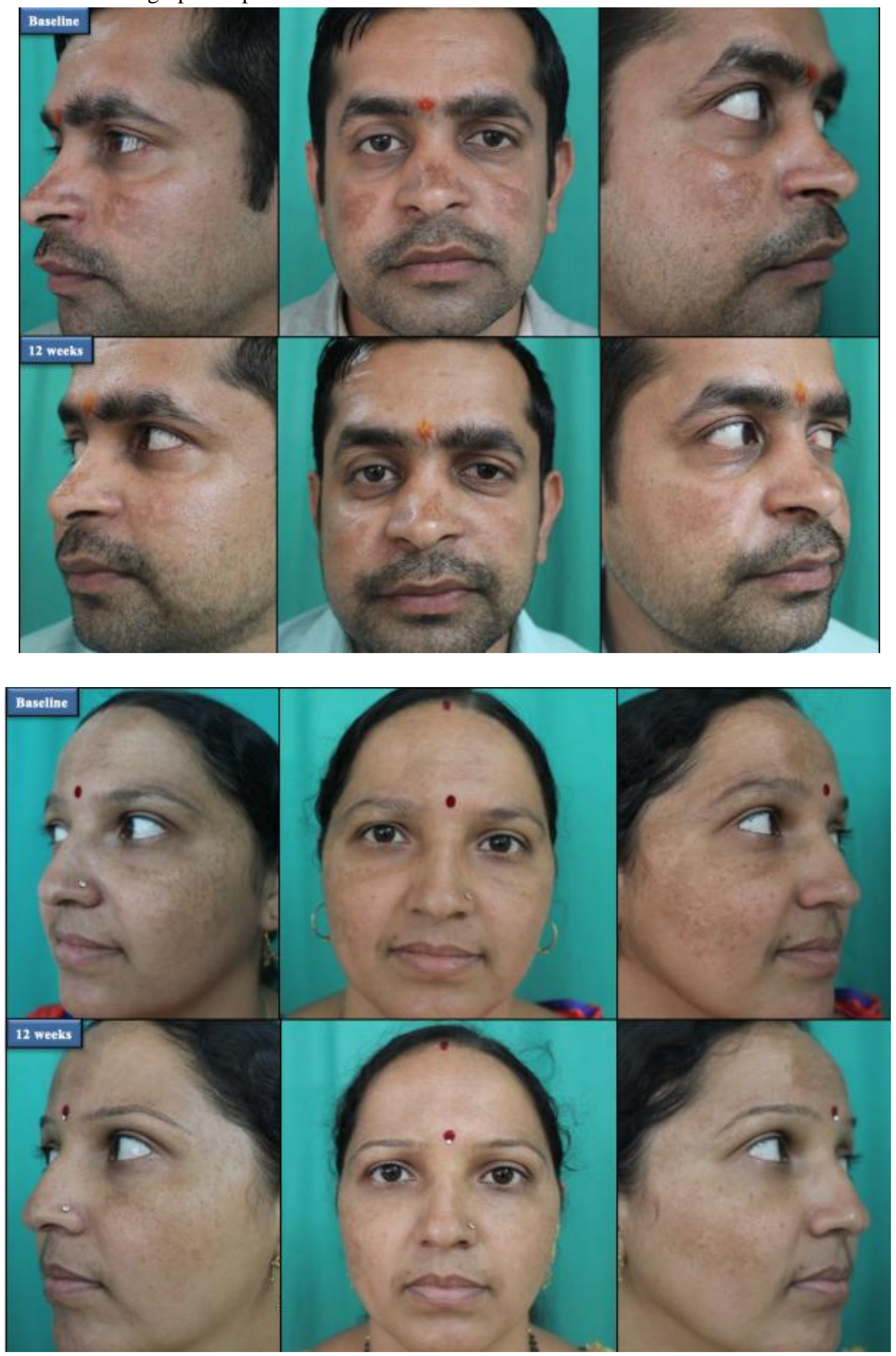


\section{JMSCR Vol||06||Issue||02||Page 151-162||February}

Figure 6 and 7: Photographs of patients treated with Tranexamic acid Cream
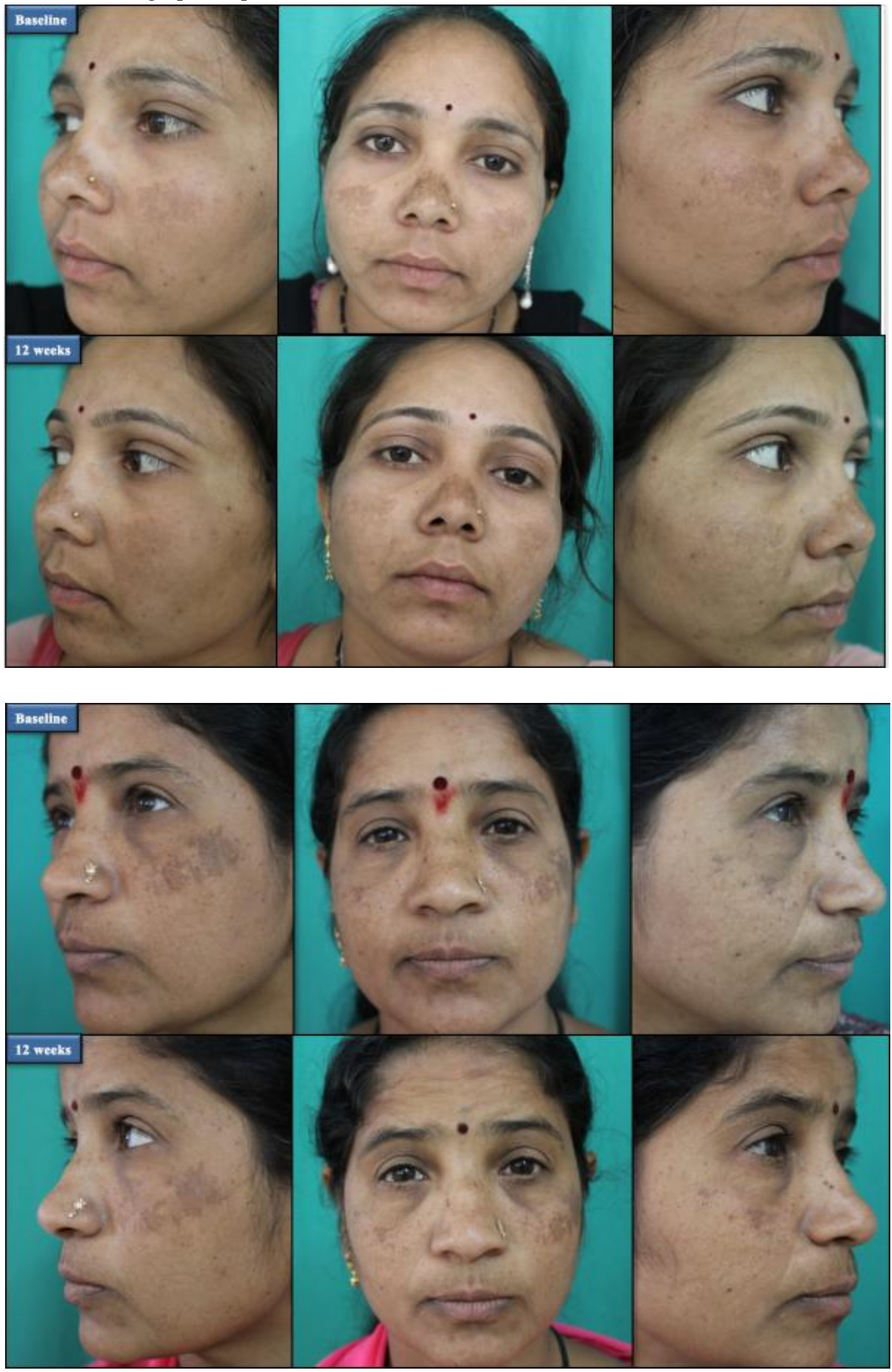


\section{Discussion}

A total of 99 patients were enrolled in the study after fulfilling the inclusion and exclusion criteria out of which 90 patients completed the study. 30 of them received oral tranexamic acid (group O), 30 received tranexamic acid soaks (group $S$ ) and the other 30 received topical tranexamic acid (group T) for 12 weeks duration. 9 patients dropped out due to travelling expenses, financial problems but none of them dropped out due to side effects which was confirmed on telephone conversation.

Melasma predominantly is clinically characterized by blotchy hyper pigmentation of the face particularly the forehead and malar eminences and to a lesser degree lower portion of the cheeks, chin, the upper lip and the sides of the neck. ${ }^{6}$ Treatment of melasma using tranexamic acid is a novel concept. ${ }^{7}$

Nijor in Japan first studied and reported action of tranexamic acid on melasma in 1979. It was accidental discovery in a patient who was treated with tranexamic acid for chronic urticaria. Since then, studies have been described the administration of tranexamic acid for treatment of melasma. $^{8}$

Tranexamic acid is widely used as antifibrinolytic agent, it has recently been found to inhibit plasminogen-keratinocyte interaction which decreases tyrosinase activity leading to decrease melanin synthesis by melanocytes. ${ }^{9,10}$

This is the first clinical study comparing single drug Tranexamic Acid in three different forms that is oral, soaks and cream in treatment of melasma.

\section{Dermographic data comparison}

Neema $S$ et al $^{11}$ in a cross-sectional case control study found 75 females and 25 males and age ranging from 27 to 48 years. Average age of patients was 36.03 years. Controls consisted of 36 females and 14 males and age ranging from 20 to 51 years. Their average age was 35.14 years.

Manjunath $\mathrm{KG}$ et $\mathrm{al}^{12}$ in a study explored the usefulness of dermoscope in comparison to Wood's lamp in melasma found 50 patients of which 25 were male and 25 were female. Their ages ranged between 26 and 50 years and the mean age of 39.133 years. In the current study, mean age of the patient was 34.8 and number of females was 70 and males was 20. The above studies are comparable with our study in respect to mean age which is in the forth decade. The male to female ratio is comparable with the study of Neema $\mathrm{S}$ et al. as melasma is more common in females, however in the study of Manjunath $\mathrm{KG}$ et al. the patient number was definite and male to female ratio was equal.

\section{Efficacy of medications}

In this study the decline in MASI scores along with marked improvement in PGA and VAS scores supports the conclusion that oral tranexamic acid is more efficacious followed by tranexamic acid soak and least the cream form in the treatment of melasma.

\section{Oral}

In our study 30 patients were given oral tranexamic acid $250 \mathrm{mg}$ twice daily for 3 months duration without any topical therapy. Efficacy of improvement was assessed by MASI. The mean MASI from baseline to $8^{\text {th }}$ week was $(12.93 \mathrm{v} / \mathrm{s}$ $3.51)$ that is $72.8 \%$ and in the $12^{\text {th }}$ week was $(12.93 \mathrm{v} / \mathrm{s}$ 0.54) that is $95.8 \%$ reduction. [Fig. 2\&3]

Karn D et $\mathrm{al}^{7}$ in a study on treatment of melasma with oral tranexamic acid conducted in 260 patients where patients were divided into two groups consisting of 130 patients each. First group (group A) was given routine treatment measures and oral tranexamic Acid 250mg twice daily for duration of 3 months, while second group (group B) was treated only with routine topical measures. Response was evaluated on the basis of MASI. Decrease in the mean MASI in group A patients from baseline to $8^{\text {th }}$ week was $(11.08 \pm 2.91 \mathrm{v} / \mathrm{s}$ $8.95 \pm 2.08)$ that is $27.2 \%$ and in the $12^{\text {th }}$ week was $(11.08 \pm 2.91 \mathrm{v} / \mathrm{s} 7.84 \pm 2.44)$ that is $36.3 \%$.

Better improvement in our study seen inspite of similar dose without combining with any other topical measures. Though Karn D et al reported decrease in the mean MASI, improvement was 
lower compared to current study possibly due to more number of patients enrolled in the study.

$\mathrm{Wu} \mathrm{S}$ et $\mathrm{al}^{13}$ in a study of treatment of melasma with oral administration of tranexamic acid in 74 patients prescribed a dosage of $250 \mathrm{mg}$ twice daily for a period of 6 months. Improvement in the pigmentation was observed by clinical and photographic assessment and were graded as: excellent, good, fair and poor. At the end of the study improvement shown was excellent to good $(64.8 \%)$.

Aamir S et $\mathrm{al}^{14}$ in descriptive cross sectional study of oral tranexamic acid in treatment of melasma in Pakistani population : a pilot study conducted in 65 patients of melasma with oral tranexamic acid $250 \mathrm{mg}$ twice a day for 6 months duration. Improvement in the pigmentation was graded as excellent, good, fair and poor. Improvement seen at the end of the study was $86 \%$.

Highest result seen in our study was possibly due to a smaller study group and efficacy parameter used was well established severity index (MASI) and not by clinical and photographic assessment as in the study of Wu S el al.

\section{Soaks}

Our's is the first study which evaluate use of tranexamic acid solution in the form of wet dressing in melasma. The idea of using tranexamic acid wet dressing in melasma was taken from the following studies. In the current study 30 patients were given wet dressing of tranexamic acid soaks 1 ampoule of $5 \mathrm{ml}$ thrice a week for 3 months duration without any adjuvant therapy. Efficacy of improvement was assessed by MASI, PGA and VAS. The reduction in the mean MASI from baseline to $12^{\text {th }}$ week was $49.6 \%$ which was fair. [Fig. 4\&5]

Kung Kim et $\mathrm{al}^{15}$ report a case of dramatic improvement of long lasting post-inflammatory hyper pigmentation by oral and topical tranexamic acid. He used wet dressing of tranexamic acid solution 3 ampoules, total $15 \mathrm{ml}(500 \mathrm{mg} / 5 \mathrm{ml})$ which was to be applied for 20 minutes three times a week along with oral tranexamic acid 250 $\mathrm{mg}$ thrice a day to reduce post inflammatory hyper pigmentation due to IPL. Two weeks of treatment there was significant improvement in the facial lesion. The above is a case report and the result is of that of single patient as compared to our study which had a larger sample size. This difference in result is due to adjuvant use of oral tranexamic acid and higher dose of tranexamic acid solution used. When only tranexamic acid solution at a one ampoule thrice weekly dose is used, effects were seen at 6 weeks. Also, the percentage of improvement was evaluated on an objective base as compared to our established efficacious parameter (MASI).This may also attribute to the better result seen in the case report of Kung Kim et al.

Kim M S et $\mathrm{al}^{16}$ in a study of tranexamic acid solution soaking as an excellent approach for rosacea patients, in this study a preliminary observation in six patients used wet gauze dampened with tranexamic acid $15 \mathrm{ml}$ solution $(500 \mathrm{mg} / 5 \mathrm{ml})$ which were applied for 20 minutes on the face once or twice a week. Treatment response was assessed after 4 weeks by Investigator's Quartile Score (IQS) and VAS. There was marked decrease in erythema. Improvement seen in flushing, burning and itching was remarkable and patients were satisfied as their skin felt cool and soothned. In the above study parameter assessed were based on rosacea. Marked improvement was seen within 4 weeks for rosacea with the weekly or biweekly schedule as compared to melasma which takes atleast 6 weeks for noticeable improvement.

Thus, weekly tranexamic acid solution is efficacious in the treatment of melasma. The effect can be accelerated by the use of a higher dose, oral tranexamic acid and any other adjuvant measures.

\section{Cream}

In the current study 30 patients were given tranexamic acid $2 \%$ cream for 3 months duration without any adjuvant therapy. The reduction in the mean MASI from baseline to $12^{\text {th }}$ week was 19.6\%.[Fig. 6\&7] 
Banihashemi $\mathrm{Z}$ et $\mathrm{al}^{17}$ comparative study of therapeutic effects of liposomal TXA and conventional hydroquinone in melasma, enrolled 30 women for a duration of 12 weeks. Patients blindly applied 5\% topical liposomal tranexamic acid and 4\% hydroquinone cream, to the designated sides of the face twice daily. The mean MASI scores significantly reduced in both treated sides after 12 week. A greater decrease was observed with liposomal TA, although this difference was not statistically significant. The better result in the above study was due to the liposomal formulation and the higher strength of the cream.

Atefi $\mathrm{N}$ et $\mathrm{al}^{18}$ in randomized double blind clinical trial in 60 patients divided between two groups: group A received tranexamic acid 5\% topically twice daily for 12 weeks and group B received hydroquinone $2 \%$. There was $52 \%$ improvement in MASI score in group A and $48 \%$ in group B. In the above study the strength of tranexamic acid was more than double (5\%) as compared to the current study. This point itself is responsible for the better improvement inspite of the treatment duration being the same.

Steiner $\mathrm{D}$ et $\mathrm{al}^{19}$ in an open, comparative and randomized study evaluating the efficacy of topical and injected tranexamic acid in treatment of melasma conducted in 18 patients divided into two groups. group A received topical application of $3 \%$ tranexamic acid twice daily and group B received application of intradermal injections of tranexamic acid $(4 \mathrm{mg} / \mathrm{ml})$ weekly for 12 weeks. At the end of the study mean MASI in group A was $22.04 \%$ and in group B $36.07 \%$. The above study is similar to ours with respect to the formulation used and duration, however 3\% strength of the cream was slightly higher. Thus, the results were comparable between both the studies.

Hence, we learn that the higher strength and good delivery system like liposomal based cream gives a better result in the treatment of melasma.

\section{Safety}

In our study we observed that $13.3 \%$ patients receiving oral tranexamic acid showed one or more side effects during their visits like headache which was the most common complaint seen in $6.7 \%$ patients followed nausea in $6.6 \%$ patients. Patients on tranexamic acid soaks and tranexamic acid cream showed no side effects.

Steiner et $\mathrm{al}^{19}$ in a study evaluating the efficacy of topical and injected tranexamic acid in treatment of melasma found side effects like erythema and burning with topical application of $3 \%$ tranexamic acid cream.

$\mathrm{Wu} \mathrm{S}$ et $\mathrm{al}^{13}$ in a study of treatment of melasma with oral administration of tranexamic acid demonstrated no obvious side effects of the treatment except gastrointestinal discomfort (5.4\%) and hypomenorrhea (8.1\%), but no serious side effects were found.

Lee et $\mathrm{al}^{18}$ in a study of oral tranexamic acid in the treatment of melasma: a retrospective analysis reported side effect of bloating and headache in $7.1 \%$ of patients.

Thus, the adverse effects in the current study are comparable with the above studies however, no major laboratory and clinical side effects were observed.

\section{Limitations of the Study}

1) This study was not a double blind-study.

2) Follow up of patients to assess the duration of clinical remission and relapse rate were not studied.

3) Longer duration and double blind studies are needed for better results with soak and cream formulation.

\section{Conclusion}

1) Oral tranexamic acid, tranexamic acid soaks and tranexamic acid cream are efficacious in the treatment of melasma.

2) Oral tranexamic acid is more efficacious followed by tranexamic acid soaks.

3) Tranexamic acid cream is the least effective. 
4) The onset of response with oral tranexamic acid starts rapidly after 1 month as compared to tranexamic acis soaks followed by cream in the current study.

5) For better results tranexamic acid soaks and cream are required to be combined with other treatment modalities.

6) Higher dose and duration of treatment are required for better results with tranexamic acid soaks and cream formulations.

7) Proper counseling regarding physical sun protection is necessary for better results.

8) Serious side effects like GI disturbances, oligomenorrhoea, hypomenorrhea, skin irritation, burning sensation or any other irreversible side effects are not observed in this study.

\section{Acknowledgments- None \\ Source of Support- None \\ Conflict of interest- None}

\section{References}

1. Jimbow, K. and Minamitsuji, Y. (2001), Topical therapies for melasma and disorders of hyperpigmentation. Dermatologic Therapy, 14: 35-45.

2. Agostoni A, Marasini B, Cicardi M, Martignoni G, Uziel L, et al. (1978) Hepatic function and fibrinolysis in patients with hereditary angioedema undergoing long-term treatment with tranexamic acid. Allergy 33: 216-221.

3. Wang N, Zhang L, Miles L, Hoover-Plow J. Plasminogen regulates proopiomelanocortin processing. J Thromb Haemost. 2004;2:785-96.

4. Chang WC, Shi GY, Chow YH, Chang LC, Hau JS, Lin MT, et al. Human plasmin induces a receptor-mediated arachidonate release coupled with G proteins in endothelial cells. Am J Physiol. 1993;264:C271-81.

5. Ando H, Matsui MS, Ichihashi M. Quasidrugs developed in Japan for the prevention or treatment of hyper pigmentary disorders. Int $\mathrm{J}$ Mol Sci. 2010;11:2699-700.

6. Poojary S, Minni K (2015) Tranexamic Acid in Melasma: A Review. Pigmentary Disorders 2: 228 doi:10.4172/23760427.1000228

7. Jae Kyung Kim, Sung Eun Chang, Chong Hyun Won, Mi Woo Lee, Jee Ho Choi, Kee Chan Moon. Dramatic Improvement of Long Standing Post-Inflammatory Hyperpigmentation By Oral and Topical Tranexamic acid. Journal of Cosmetics, Dermatological Sciences and Vpplications, 2012, 2, 62-63

8. Neema S, Chatterjee M. Dermoscopic Characteristics of Melasma in Indians: A Cross-sectional Study.Int J Dermoscop 2017;1(1):6-10.

9. Maeda K, Naganuma M. Topical trans-4aminomethyl cyclohexanecarboxylic acid prevents ultraviolet radiation-induced pigmentation. J Photochem Photobiol B. 1998;47:136-41.

10. Kanechorn Na Ayuthaya P, Niumphradit N, Manosroi A, Nakakes A (2012) Topical $5 \%$ tranexamic acid for the treatment of melasma in Asians: a double-blind randomized controlled clinical trial. J Cosmet Laser Ther 14: 150-154.

11. Pichardo R, Vallejos Q, Feldman SR, Schulz MR, Verma A, Quandt SA, et al. The prevalence of melasma and its association with quality of life in adult male Latino migrant workers. Int $\mathbf{J}$ Dermatol. 2009;48:22-6.

12. Sufan Wu, Hangyan Shi, Hua Wu, Sheng Yan, Jincai Guo, Yi Sun, Lei Pan. Treatment of melasma with oral administration of tranexamic acid Aesthetic Plastic Surgery 2012;36(4): 964-70

13. Aamir S, Naseem R. Oral tranexamic acid in treatment of melasma in Pakistani population: a pilot study. Journal of Pakistan Association of Dermatologists 2014;24 (3):198-203 
14. Kim K, Chang SE, Won CH, Lee M W, et al. "Dramatic Improvement of Long Lasting Post-Inflammatory Hyper pigmentation by Oral and Topical Tranexamic Acid," Journal of Cosmetics, Dermatological Sciences and Applications, Vol. 2 No. 2, 2012, pp. 62-63.

15. Kim MS, Chang SE, Haw S, Bak H, Kim YJ, Lee MW (2013), Tranexamic acid solution soaking is an excellent approach for rosacea patients: A preliminary observation in six patients. The Journal of Dermatology 2012;40: 70-71

16. Banihashemi, M, Zabolinejad, N, Jaafari, MR, Salehi M, Jabari A. Comparison of therapeutic effects of liposomal Tranexamic Acid and conventional Hydroquinone on melasma. Journal of Cosmetic Dermatology 2015;14:174-177

17. Atefi N, Dalvand B, Ghassemi M, Mehran G, Heydarian A. Therapeutic Effects of Topical Tranexamic Acid in Comparison with Hydroquinone in Treatment of Women with Melasma. Dermatology and Therapy . 2017;(3):417-424

18. Lee HC, Thng TG, Goh CL (2016). Oral tranexamic acid in the treatment of melasma: A retrospective analysis. Journal of The American Academy of Dermatology, 75, 385-392.

19. Tse TW, Hui E (2013) Tranexamic acid: an important adjuvant in the treatment of melasma. J Cosmet Dermatol 12: 57-66. 